\title{
Design of a Link Road to Connect the Beitbridge- Chirundu Highway to Harare Drive in Harare, Zimbabwe
}

\author{
Joan R. Shumba ${ }^{1}$, Samson Shumba $^{2}$, Liliana D. Vassileva ${ }^{3}$, Namatirai Cheure ${ }^{4}$ \\ \{shumbajoan@gmail.com, sshumba08@gmail.com, vassileva@eng.uz.ac.zw\} \\ Department of Civil Engineering, Faculty of Engineering, University of Zimbabwe, P.O \\ Box MP167 Mount Pleasant, Harare
}

\begin{abstract}
The project focussed on the design of a link road to connect the BeitbridgeChirundu Highway to Harare Drive and Kirkman Road in Harare, Zimbabwe. The proposed link road is approximately $17 \mathrm{~km}$ long. The link road will alleviate traffic flowing into Harare by linking the missing portion of Harare drive a ring road to a major highway. A manual traffic count was carried out to determine the percentage of heavy vehicles in transit on the highway. The results were compared to historic traffic counts. The analysis was carried out using QGIS and AchiCAD softwares, Microsoft excel and AutoCAD. The geometric design of the link road and intersection was carried out based on guidelines for Southern Africa roads. The link road and grade separated intersection with a design life of 20 years was designed. It is recommended that traffic flow be diverted and extra caution be taken during the construction.
\end{abstract}

Keywords: Highways, Traffic congestion, Ring Road, Grade Separated Intersection and Geometric Design.

\section{Introduction}

\subsection{Background}

Major cities throughout Zimbabwe are experiencing considerable increases in population, consequently the traffic demand on each city's transportation infrastructure has also increased. The rapid increase in car ownership contributes to the unmanageable flows of traffic thereby reducing the efficiency of the road network. The efficiency of the transportation system greatly affects safety of road users as well as the economy of the country [1]. Transport is one of the most important factors in making a nation prosper. Roads are the most heavily used mode of transport for people and business. Thus, the road network is vital to our economy and to our way of life. The majority of roads in developing countries are rural and urban highways, which are used by both slow and fast moving traffic. The design of new roads or improvement to existing roads should be based on the future traffic expected to use the facilities.

ACRID 2017, June 20-21, Victoria Falls, Zimbabwe

Copyright (C) 2017

DOI 10.4108/eai.20-6-2017.2270749 


\subsection{Problem Statement}

Traffic congestion on urban roads and intersections is becoming an ever increasing problem to road users especially in Harare [2]. Hence, there is a need to curb congestion and ideally increase capacity. Congestion results in physical costs such as fuel costs and depreciation of vehicles as well as environmental costs associated with noise and air pollution [3]. The increase in traffic volume is also contributed to the number of haulage trucks that pass through Harare in transit to Chirundu. Currently the traffic entering Harare from Beitbridge diverts into High Glen. Therefore, to solve the problems, there is need to design a road to deviate the traffic flowing into the city. Since additional road building in the Central Business District is physically impossible, this can be achieved by deviating traffic flowing on the Beitbridge -Chirundu Highway via Harare. In this study, an alternative link road will be proposed, paying particular attention to the design of an intersection between the proposed link road and the existing portion of Harare drive.

\subsection{Justification of the Project}

An efficient road network can reduce travel times, improve reliability and improve air quality. A link road is a transport infrastructure that links major road facilities, often added when there is an increase in traffic. Furthermore, link roads help get goods to the market and link major economic centres. Therefore, a high quality road network construction leads to an increase in the nation's economy and its output.

Considering Zimbabwe's economic environment there is need to design efficient intersections which can accommodate current and future traffic flows. Intersections are designed so as to carry all types of transport systems. The ability of an intersection to accommodate high volumes of traffic safely and efficiently depends on how intersecting traffic is handled. The highest capacity can be attained when the intersecting traffic is grade separated and this can be concluded from high operating speeds associated with grade separated intersections.

\subsection{Study Area}

Figure 1 highlights the Beitbridge-Chirundu highway, the study area is the Harare drive/ Kirkman road intersection. The intersection has 3 legs and it is located west of Harare central business district. Harare drive is a ring road mainly found in the northern part of Harare. 


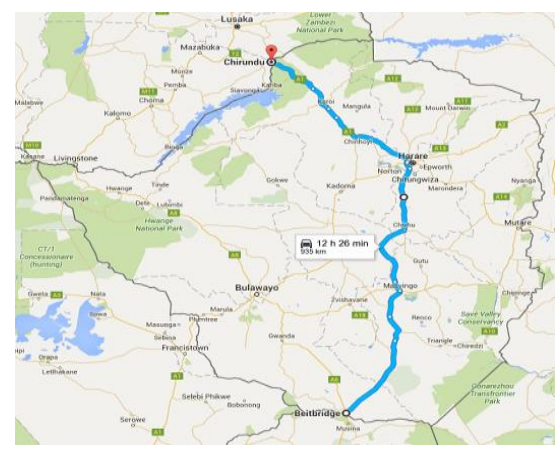

Fig. 1. Beitbridge-Chirundu Highway from Google earth imagery

\section{Literature Review}

\subsection{What Is A Link Road?}

In the context of junctions, a link road is a connector road adjacent to but separate from the mainline carriageway. It is used to connect the mainline carriageway to the local highway network. This is usually done where successive direct connections cannot be provided to an adequate standard because the junction spacing will be close [4]. A ring road is a road that goes around the edge of a town, allowing traffic to avoid the town centre.

Outer Ring road. Studies have concluded that the benefits of a ring road where enhanced connectivity opportunities between major employment nodes; connectivity between industrial areas; reduction of heavy vehicles on roads within the city; link trade corridors and alleviate congestion in and around the city. Furthermore, an outer ring road results in improved traffic management.

\subsection{What Is An Intersection?}

An intersection is the area where two or more streets join or cross [5]. Its main function is to enable road users to turn to different directions to reach their desired destinations by guiding vehicles to their respective directions. The main objective of intersection designs is to minimize the magnitude and the characteristics of road conflicts and to simplify the driver route selection process. Consequently, the design of the intersection should enable drivers to discern quickly from the layout the path to follow. Furthermore, the type of intersection determines safety, delays, efficiency and capacity of the system. For an intersection to be efficient also considering the safety and comfort of road users, an apt analysis on selecting the most suitable intersection design type for an area should be carried out [6].

\subsection{Basic Principles of Intersection Design}

The basic principles of intersection design are outlined below [5]: 
i. Minimise the conflict area: The number of conflict points can be reduced by staggering, channelization and prohibition of some movements. T and Y intersections usually have collisions that result from unanticipated vehicle manoeuvres.

ii. Control the angle of potential vehicle conflict: To enable vehicles to accelerate and merge with the through traffic easily, the merging angles should be small, that is, between $10^{\circ}$ to 15 .

iii. Provide appropriate signs and markings: Advance warning signs should be provided on minor roads, on all roads where intersections are obscured and where it is desirable for vehicles to slow down such as on high speed roads.

iv. Minimise delays and hazards: The layout of the intersection should favour the heaviest and fastest flows thereby improving the capacity of the intersection as well as safety.

v. Provide adequate visibility: Posts/poles with traffic control signage must be at a safe location that does not obstruct the road user. Also, lighting must be provided for night illumination.

vi. Control access to developments in the vicinity of the intersection: Driveways should not be permitted within the area of immediate influence.

Interchanges and Grade-separated intersections. An interchange is a system of interconnecting roads (referred to as ramps) in conjunction with one or more grade separations. It caters for the movement of traffic between two or more roadways which are at different levels at their crossing point [7]. A grade-separated intersection is a junction of two or more roads that have been aligned at different heights so that traffic flow on other transit routes is not disrupted at the point of intersection. Grade-separation of traffic flows allows the heaviest traffic flow to pass unhindered through the intersection whilst lighter traffic flows including all turning movements are catered for on separate levels. Figure 2 illustrates types of grade separated intersections.
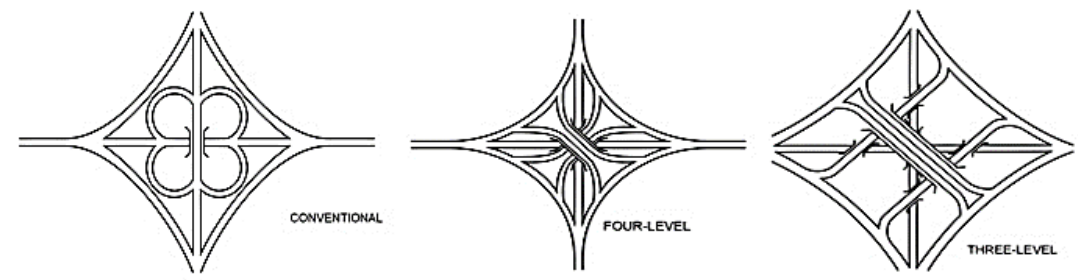

Fig. 2. Examples of grade separeted intersections [7]

\section{Advantages}

i. Free and comfortable movement of high volume traffic even at high speeds due to full control of access.

ii. Improved capacity of intersections of major highways and minimal rate of accidents

iii. Better in economic terms, in view of overcoming traffic delays as linked to time cost to operators.

iv. In areas where the topography requires extensive excavations when levelling as efforts to put at grade intersections, it will be less expensive to put an interchange.

\section{Disadvantages}

i. Require very high capital cost. 
ii. They require large amounts of land for construction. Thus, it is recommended that a serious assessment of the economy, the operation and environment around the site be carried out to ensure that the form of intersection is justified in long term.

\section{Grade Separated Intersection Design}

\subsection{Factors Influencing the Construction of Grade Separated Intersections}

The following are some of the factors that influence the construction of grade separated intersections.

i. Grade separations are preferred where traffic volumes at an intersection are high enough that a hypothetical at-grade intersection would warrant a traffic signal [8].

ii. At- grade intersections are susceptible to vehicle- contact type accidents regardless of their design or signalization. Therefore, by separating the grades of the intersecting roadways accidents can be reduced.

iii. Grade separations remove a significant portion of the conflict area.

iv. Grade separated intersections are used to reduce spot congestions or bottlenecks at intersections.

v. A grade separated intersection is preferable when the long term operating and maintenance benefits outweigh the initial cost of construction.

\subsection{Evaluation of Design Alternatives}

The evaluation is based on the capacity adequacy, land requirements and costs associated. The volume of conflicting traffic must be reduced in order to increase safety. This can be achieved by giving traffic on the highway (Harare drive) priority. There are four possible grade separated intersection designs that can be considered.

Diamond interchange. A diamond interchange has four ramps, these enter and exit the freeway at small angles and meet the non-freeway at almost right angles. These ramps are usually controlled by traffic signals. Diamond interchanges have a low capacity and high signalized delay. In addition, there is need for proper channelization to avoid wrong movements on slip roads.

Roundabout interchange. The roundabout interchange has the main highway under passing or over passing a roundabout. Operation is similar to that of a diamond interchange, traffic leaves and enters directly. However, if the traffic exceeds the predicted traffic, operational problems may arise with queuing vehicles on the roundabout entries. Furthermore, it has high structural costs.

Full clover leaf. A full clover leaf in an interchange with loops on its quadrants. This option would improve traffic circulation but at significantly higher costs, which overall has lower economic returns. In addition, because of the 4 loops, full clover leafs use up large amounts of land. 
Partial clover leaf. The partial clover leaf is a modified full clover leaf. Provides higher levels of service and high capacity. The road will operate as a major highway with mean speed. There is low signalized delay on minor road. Furthermore, construction and operational costs are relatively lower compared to other interchanges.

\section{Methodology}

\subsection{Field Studies}

From reconnaissance and maps acquired from the Surveyor General's office, it has been seen that the site has enough land space for lateral expansion. The areas that are close to the proposed link road are Sourtherton, Ardbennie and Willowvale. These are industrial and residential areas. The areas adjacent to the intersection include Warren Hills, Westlea and the National Sports Stadium.

The elevations of the area around the intersection were used to determine if the ground is level, rolling or mountainous. The elevations were obtained from using geographical information system software (QGIS). It showed that the area is of level terrain.

\subsection{Traffic Counts}

In the project, traffic counts were conducted at the $21 \mathrm{~km}$ peg along Simon Mazorodze. The proportion of turning vehicles was assumed. Many vehicles are assumed to use the route since it links the new suburbs such as Southlea Park and Amalinda to the Central business district. Furthermore, the highway is of economic importance as it links Zimbabwe to its major trading partners, hence more heavy vehicles and haulage trucks use the highway. Currently, plans of dualisation of Simon Mazorodze are underway.

The recommended methods for conducting traffic count surveys are that, counts should be carried out on normal working days. According to the manuals from the Ministry of transport, traffic counts should not be carried out when travel activities are abnormal for short periods such as; on public holidays or days when there are sporting events. Furthermore, the counts should not be done when there is a heavy rainfall; when there is temporal road closure due to construction works or road blocks [9]. In accordance to what is stated above, the traffic count survey was conducted in 2016 on the following days: 18 - 20 January. The traffic data gathered for design purposes normally includes morning, afternoon and evening peak period traffic volumes.

Traffic is presented in vehicles per hour and passenger car units per hour and there is a total for both forms for each peak on every approach. The traffic was classified using the vehicle classification and conversion factors from the Ministry of Transport that are represented in Table 1.

Table 1. Conversion Factors

\begin{tabular}{ll}
\hline Vehicle & Conversion Factor \\
\hline Light vehicle & 1.0 \\
Mini bus & 1.2 \\
Bus & 1.5 \\
Heavy vehicles & 1.7 \\
Haulage trucks & 2.0 \\
\hline
\end{tabular}


Analysis of Manual Traffic Count Data. Table 2 shows the traffic data that was recorded on Monday evening. The data was recorded in 5-minute intervals.

Table 2. Traffic volume pcu/hr/lane

\begin{tabular}{lllllll}
\hline DAY & $\mathbf{1 8 / 0 1 / 2 0 1 6}$ & & & & & \\
\hline $\begin{array}{l}\text { APPROACH } \\
\text { 1730-1830 hrs }\end{array}$ & $\begin{array}{l}\text { To Harare } \\
\text { Light } \\
\text { vehicles }\end{array}$ & Mini Bus & Buses & $\begin{array}{l}\text { Heavy } \\
\text { vehicles }\end{array}$ & $\begin{array}{l}\text { Haulage } \\
\text { Trucks }\end{array}$ & Total \\
$0-5$ & 10 & 3.6 & 1.5 & 1.7 & 4 & 20.8 \\
$5-10$ & 7 & 0 & 0 & 0 & 4 & 11 \\
$10-15$ & 10 & 1.2 & 4.5 & 5.1 & 2 & 22.8 \\
$15-20$ & 18 & 1.2 & 0 & 1.7 & 0 & 20.9 \\
$20-25$ & 9 & 0 & 0 & 3.4 & 4 & 16.4 \\
$25-30$ & 7 & 0 & 0 & 0 & 2 & 9 \\
$30-35$ & 14 & 2.4 & 1.5 & 1.7 & 6 & 25.6 \\
$35-40$ & 12 & 1.2 & 0 & 0 & 6 & 19.2 \\
$40-45$ & 13 & 1.2 & 0 & 1.7 & 4 & 19.9 \\
$45-50$ & 5 & 0 & 1.5 & 3.4 & 8 & 17.9 \\
$50-55$ & 10 & 0 & 0 & 0 & 4 & 14.0 \\
$55-60$ & 10 & 2.4 & 0 & 1.7 & 2 & 16.1 \\
Total & 125 & 13.2 & 9 & 20.4 & 46 & 213.6 \\
\hline
\end{tabular}

The peak hour factor for the traffic that was observed during the evening peak was determined using equation 1 .

$$
\text { PHF }=\frac{Q}{N_{\mathrm{t}} x \frac{60}{t}} .
$$

Where $\mathrm{Q}=$ the number vehicles in pcu's per hour, $\mathrm{N}_{\mathrm{t}}=$ the maximum number of vehicles counted during a period $\mathrm{t}$ which is less than 1 hour and $\mathrm{T}=$ period less than 1 hour $(5,10$ or 15 mins).

$$
\text { PHF }=\frac{214}{25.6 x \frac{60}{5}}=0.7 \mathrm{pcu} / \mathrm{hr}
$$

The peak hour factor for the 10 and 15 minutes period was found to be $0.80 \mathrm{pcu} / \mathrm{hr}$ and $0.83 \mathrm{pcu} / \mathrm{hr}$ respectively.

The time headway is given in equation 2.

$$
H_{5}=\frac{3600}{q} \sec .
$$

Where, $\mathrm{h}_{\mathrm{t}}=$ time headway in seconds and $\mathrm{q}=$ flow rate in $\mathrm{pcu} / \mathrm{hr}$

Equation 2 was used to determine the headway distribution which was found to be $36 \%$, this implied gaps of 6 seconds are not readily available since the probability is low. 


\subsubsection{Historical Data}

The traffic data for 2011 to 2014 was obtained from the Ministry of Transport. It was used for analysis so as to predict the future traffic increase. The trend in traffic growth is illustrated in Figure 3.

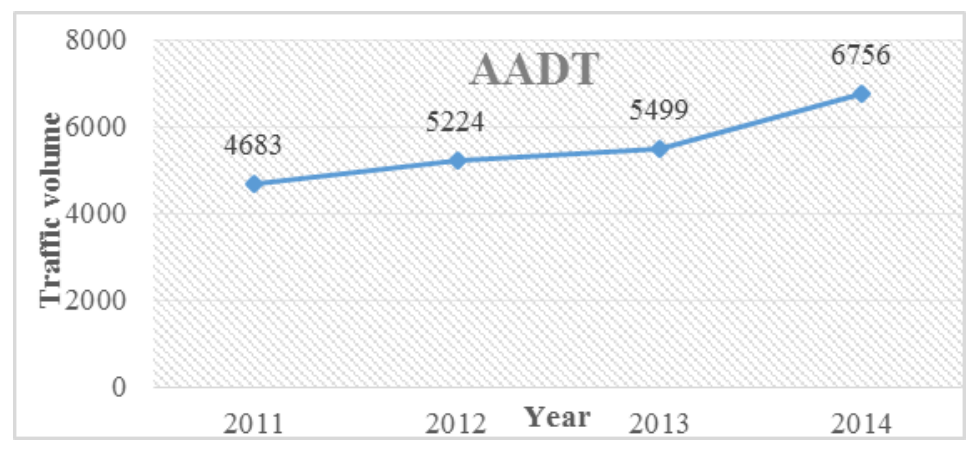

Fig. 3. AADT at Skyline $19.5 \mathrm{~km}$ peg

\section{Percentage increase:}

$>$ From 2011 to 2012

$$
\begin{aligned}
& =\frac{5224-469 a}{469 a} \times 100=12 \% \\
& =\frac{6756-5224}{5224} \times 100=29 \% \\
& =\frac{6756-469 a}{468 a} \times 100=\mathbf{4 0 \%}
\end{aligned}
$$

Traffic conditions. The road is a two way- two lane road. The traffic passing in a day consists of $20-22 \%$ of heavy vehicles as illustrated in Figure 4.

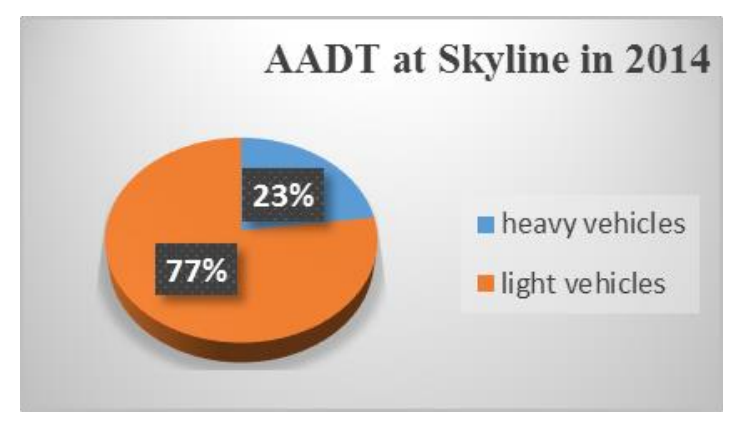

Fig. 4. Average Traffic distribution

Future traffic volumes: A typical traffic growth rate of 5\% is used according to the Ministry of Transport, with the assumption that growth is linear. However, traffic growth can be erratic due to motorization and other socio-economic factors. The design traffic is calculated using equation 3 .

\section{Traffic Growth}




$$
Q_{d}=Q x(1+r)^{n}
$$

Where, $\mathrm{Q}_{\mathrm{d}}=$ Design traffic

$\mathrm{Q}=$ Current traffic

$r=$ average traffic growth rate

$\mathrm{n}=$ number of years expected to reach the design life

The design hourly volume of traffic is determined using equation 4.

$$
\mathrm{DHV}=\mathrm{AADT} \times \mathrm{K} \text {. }
$$

Where, DHV = Design Hourly Volume

AADT $=$ Average Annual Daily Traffic

$\mathrm{K}=$ density

\section{Methodology}

\subsection{Proposed Intersections}

After evaluating the different types and forms of grade-separated intersections, a partial cloverleaf was selected for the intersection of Harare drive, Kirkman road and the proposed link road. This is because the partial clover leaf can be applied where there are relatively low turning movements from major-minor road. Table 3 shows the design details for the partial cloverleaf.

Table 3. Design Details

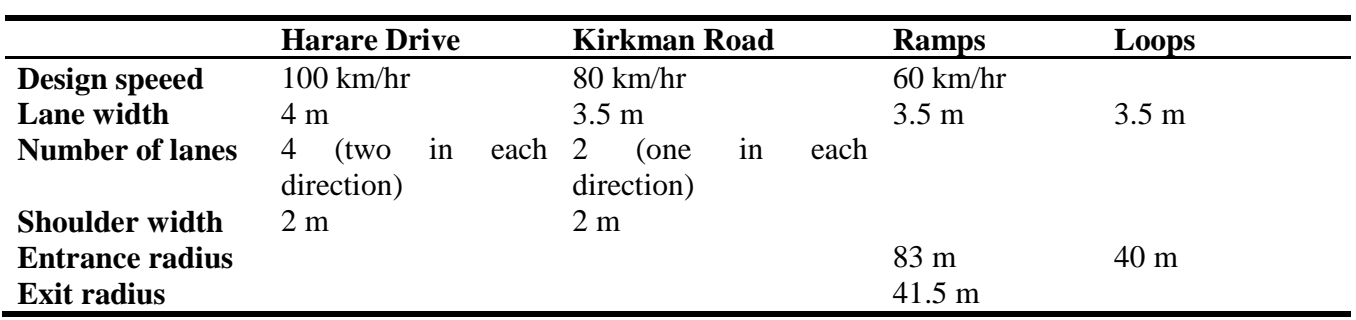

\subsection{Other Design Considerations}

\subsubsection{Pedestrian and Cyclist Facilities}

To increase the safety of pedestrians and also for their convenience crosswalks should be provided that do not result in traffic delays. Cyclists also need to be catered for by providing cycle lanes.

\subsubsection{Signage}


Another important part of intersection design is uniformity of signing. This helps to protect road users. Signs should be located and designed so as not to obstruct visibility. Some important points to consider are:

i. Traffic guide signing on exit ramps should be consistent with that on the mainline

ii. Overhead guide signing is recommended for the approaching cross road.

iii. The sign support should be placed at or just beyond the point where the left turn is fully developed.

\subsubsection{Pavement Marking}

Pavement markings are used to channelize traffic as well as indicate a dedicated lane. Lane indication arrows are used at entry or exit points where heavy flows occur in a certain direction. Lane dedication is used where there are three or more lanes. Lights shall be located in such a way that they provide good illumination.

An example of the expected final outcome modelled in ArchiCAD is illustrated in Figure 5.

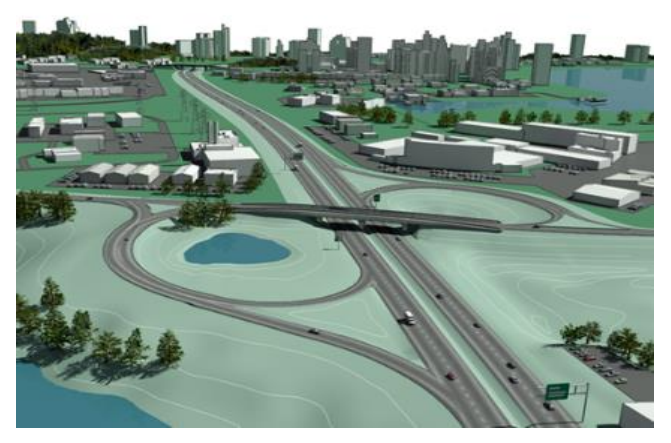

Fig. 5. Partial Clover leaf model

\section{Conclusions and Recommendations}

\subsection{Conclusions}

The geometric design of the proposed link road and intersection has been accomplished. The horizontal and vertical alignments have been carried according to standard specifications for Southern Africa and Zimbabwe. The final design has a 20 year design life. Stop signs have been proposed at entry points of the terminals where road users on the minor road need an acceptable gap to merge into the through traffic.

\subsection{Recommendations}

Since the proposed route area covers residential and industrial areas local traffic flow should be diverted and extra caution should be taken during the construction. Furthermore, the overhead signing is recommended for the approaching cross road. The grade separated 
intersection should have more columns for aesthetic reasons. Also the drainage system should be designed and the retaining wall for the rising roads.

\section{References}

[1] Oglesby, C. and Hicks, R.: Highway Engineering, 4th ed. John Wiley \& Sons (1982)

[2] Zimbabwe Report, Road Transport Services and Infrastructure, Harare (1996)

[3] Triantis, K., Sarangi, S., Teodorovic, D. and Razzolin, L.: Traffic congestion mitigation :

combining engineering and economic perspectives 1060. doi:10.1080/03081060.2011.602845 (2015)

[4] Design Manual for Roads and Bridges. Geometric Design of Roundabouts, TD16/07 ed, Road Geometry, Section 2 Junctions. (2007)

[5] Overseas Road Note 6.: A guide to geometric design. Roughton and Partners, Berkshire: Highway Engineering, 4th ed. John Wiley \& Sons (1988)

[6] O'Flaherty, C.A.: Highways: Highway Engineering. Edward Arnold, Wallingford (1986)

[7] South African National Roads Agency.: Interchanges, Geometric Design Guide, South africa (2006)

[8] Road Design Manual.: Interchange and Grade Separations (2001)

[9] O'Flaherty, C.A.: Traffic Planning and Engineering. Edward Arnold, Wallingford. (2002) 